\title{
Prevalence of Mycotoxins in Late-Season Corn Ear Molds in North Dakota
}

\author{
Joel Ransom ${ }^{1 *}$, Kasia Kinzer², Marcia McMullen³, Michelle Mostrom4, Itai Mutukwa1, \\ Andrew Friskop ${ }^{3}$ \\ ${ }^{1}$ Plant Sciences Department, North Dakota State University, Fargo, ND, USA \\ ${ }^{2}$ University of Idaho, Idaho Falls, ID, USA \\ ${ }^{3}$ Plant Pathology Department, North Dakota State University, Fargo, ND, USA \\ ${ }^{4}$ Veterinary Diagnostic Services, North Dakota State University, Fargo, ND, USA \\ Email: "joel.ransom@ndsu.edu
}

Received 28 January 2016; accepted 27 March 2016; published 30 March 2016

Copyright (C) 2016 by authors and Scientific Research Publishing Inc.

This work is licensed under the Creative Commons Attribution International License (CC BY).

http://creativecommons.org/licenses/by/4.0/

(c) (i) Open Access

\begin{abstract}
Widespread corn ear mold development in North Dakota and in other states was associated with cool, wet weather after physiological maturity in 2009. In response to concerns about possible grain mold and mycotoxin contamination in North Dakota, a survey of corn ear diseases was conducted in 2009 prior to harvest. Corn ears were collected from 94 field locations from 24 counties and were examined macroscopically and microscopically for mold identification. Mycotoxin testing was done with a screen for 17 tricothecenes using gas chromatography/mass spectrometry techniques. Cladosporium was the most commonly identified fungus with some Fusarium contaminated samples being observed. Other fungi identified include Alternaria, Penicillium, Aureobsidium, Rhizopus, Stemphylium and an unidentified non-pigmented fungus. Five mycotoxins were identified in 25 out of the 94 samples; deoxynivalenol, T-2, HT-2, zearalenone and nivalenol. Of the mycotoxin-positive samples, $88 \%$ had less than 2 ppm of any mycotoxin. Despite the growing season's weather being favorable for corn ear mold development late in the season, observed mycotoxin levels were surprisingly low and most grain was deemed safe for use in food and feed channels. Surveys were planned in subsequent years, but late season molds did not develop in the 2010-2015 growing seasons.
\end{abstract}

\section{Keywords}

Deoxynivalenol, Disease Survey, Corn Diseases, Ear Rots

\footnotetext{
"Corresponding author.
}

How to cite this paper: Ransom, J., Kinzer, K., McMullen, M., Mostrom, M., Mutukwa, I. and Friskop, A. (2016) Prevalence of Mycotoxins in Late-Season Corn Ear Molds in North Dakota. American Journal of Plant Sciences, 7, 709-714. 


\section{Introduction}

A number of fungi can colonize and cause diseases of corn (Zea mays L.) [1]. Corn ear molds are a special concern because of the possibility that the infected grain will contain mycotoxins, a group of secondary metabolites produced by some fungi that can be toxic to mammals [2]. Because of the risk of this toxicity, it is recommended that grain that has field mold should be tested for mycotoxins before it is used for feeding [2] [3]. When animals feed on mycotoxin-infested grain, damage to their organ systems, detrimental effects on production and reproduction and lowered immunity may occur resulting in an increased vulnerability to disease [2].

Most ear and kernel molds of corn occur as a result of damage to the ear by insects, birds, weather events, or when the ear lays on the ground due to plant lodging [1]. However, during the 2009 growing season weather conditions were conducive for the development of ear molds over a wide geographical area on otherwise healthy, standing corn. This raised concern by those purchasing corn about the prevalence of mycotoxin contamination. The cool spring and a cooler than normal summer weather resulted in a slower accumulation of growing degree days [4], so corn matured later than normal. With most of the corn crop still in the field, grain containing more moisture than normal, combined with the wet and cool weather conditions experienced in October, corn ear molds developed throughout most of the state and in most fields. A study was conducted to determine the extent of fungal and mycotoxin contamination on corn ears at the end of the 2009 North Dakota growing season. Similar surveys were planned for subsequent years (2010-2015), but ear molds did not develop so no data were collected.

\section{Materials and Methods}

Weather data were analyzed for the 2009 season in order to identify weather-related factors that were associated with the widespread corn ear molds that developed. Data from the North Dakota Agricultural Weather Network [5] were used in this analysis.

North Dakota State University County Extension Agents and Area Extension Specialists collected corn ear samples from 65 fields distributed in 24 counties in North Dakota during the second week of November. Each sample consisted of ten corn ears that were randomly selected from fields that were arbitrarily selected by the respective county/area agent in each county. The number of fields sampled within a county were based on the number of acres grown to corn, with four fields being sampled from the counties with the most corn acres. Ears were de-husked and placed in paper bags for shipping and all samples were received within 24 hours of harvest. Observations were made on all cobs from a given sample. However, no data on the frequency of fungi detected within the ten-cob sample were recorded. An additional 29 samples that had been submitted to the plant diagnostic lab by interested growers were included in this study. These samples were known to have mold problems by the providers and were not randomly selected from the field as were those previously described. Thus, a total of 94 samples that represented the most important corn growing areas of the state were analyzed.

Samples were examined macroscopically and microscopically in order to identify molds. For samples without fungal sporulation, kernels with mycelia only were arbitrarily selected for culturing to promote sporulation. These kernels were surface-sanitized and incubated on half-strength potato dextrose agar for up to ten days. If no sporulation was observed, the fungus remained unidentified. Mold identification in all cases was based on color of fungal hyphae and morphological characteristics of spores.

After drying, ground corn kernels from each of the 94 samples were screened for the presence of 17 tricothecenes using gas chromatography/mass spectrometry at the North Dakota State University Veterinary Diagnostic Lab using the procedures described by Mirocha et al. [6]. Based on the results from fungal identification, no Aspergillus was identified on any of the corn samples and hence aflatoxin was not included in the mycotoxin screens.

\section{Results and Discussion}

\subsection{Weather Data}

Monthly temperature and precipitation data for September-October of 2009 as well as the normal temperature and precipitation means for North Dakota are summarized in Table 1 [5]. The wet spring and cool summer experienced in 2009 resulted in the accumulation of fewer growing degree days during the growing season, subsequently harvest was delayed. Of particular importance were the prevailing conditions at the end of the growing 
Table 1. Precipitation totals and average monthly temperature in 2009 compared to normals for selected weather stations in North Dakota [5].

\begin{tabular}{|c|c|c|c|c|c|}
\hline Month & Weather Stations & Average 2009 Temperature & $\begin{array}{c}\text { Normal } \\
\text { Temperature }\end{array}$ & $\begin{array}{c}\text { Average } 2009 \\
\text { Precipitation }\end{array}$ & $\begin{array}{c}\text { Normal } \\
\text { Precipitation }\end{array}$ \\
\hline & & $\left({ }^{\circ} \mathrm{C}\right)$ & $\left({ }^{\circ} \mathrm{C}\right)$ & $(\mathrm{mm})$ & $(\mathrm{mm})$ \\
\hline \multirow[t]{7}{*}{ September } & Mandan & 18 & 14 & 53 & 39 \\
\hline & Carrington & 17 & 14 & 55 & 49 \\
\hline & Minot & 18 & 14 & 100 & 37 \\
\hline & Fargo & 18 & 15 & 50 & 65 \\
\hline & Grand Forks & 18 & 14 & 34 & 52 \\
\hline & Edgeley & 17 & 15 & 57 & 62 \\
\hline & Hettinger & 17 & 14 & 14 & 37 \\
\hline \multirow[t]{7}{*}{ October } & Mandan & 3 & 7 & 69 & 35 \\
\hline & Carrington & 3 & 7 & 77 & 45 \\
\hline & Minot & 3 & 6 & 46 & 36 \\
\hline & Fargo & 4 & 8 & 137 & 55 \\
\hline & Grand Forks & 4 & 6 & 89 & 50 \\
\hline & Edgeley & 4 & 7 & 110 & 43 \\
\hline & Hettinger & 3 & 7 & 59 & 35 \\
\hline
\end{tabular}

season in October. Temperatures were lower than normal with record low minimums being set in some parts of the state and a killing frost occurred in the second week of October [7]. Precipitation was $100 \%-300 \%$ above normal in most areas of the state [5]. The state averaged $65.8 \mathrm{~mm}$ of precipitation in October far exceeding the normal state average of $25.8 \mathrm{~mm}$. These exceptionally wet conditions were conducive for ear mold development and raised the risk for the production of mycotoxins such as deoxynivalenol (vomitoxin), zearalenone, and fumonisin. The persistent wet conditions at the end of the season hindered harvesting, further increasing the risk for corn ear mold development and mold-related damage. Conditions in 2009 were also conducive for the development of late season ear molds in other parts of the Corn Belt in the USA [3].

\subsection{Fungi Species Identified and Prevalence}

The most commonly identified fungus genus (Table 2) was Cladosporium (Figure 1), found on 91 out of the 94 samples. This fungus causes a dark green to black mold growth on the corn kernel surface, between kernels or on the cob. Cladosporium, though unsightly both on the cob while growing and when dried (dark flecks in the grain), has not been reported to produce mycotoxins.

Fusarium species (Figure 2) were confirmed or suspected on 16 of the 94 samples. Fusarium fungi cause a cottony white, light grey, or possibly a pink or salmon colored mold growth on and between corn kernels [8]. Infected kernels turned grey to brown or had white streaks in them. The observed low incidence of Fusarium species may have resulted from conditions that were drier than optimum for infection at silking [9].

Non-pigmented mycelium without spore production was observed on a few ears and the casual fungus was not identified. Other molds that were observed included Alternaria, Penicillium, Aureobsidium, Rhizopus, Stemphylium and an unidentified darkly pigmented dematiaceous fungus.

\subsection{Mycotoxins Detected and Prevalence}

Mycotoxins were found on 25 out of the 94 samples tested (Table 3). The five different mycotoxins identified were: deoxynivalenol, T-2, HT-2, zearalenone and nivalenol. Mycotoxin levels were generally low, with $88 \%$ of mycotoxin-positive samples having less than $2 \mathrm{ppm}$. The remaining $12 \%$ of the samples that tested positive for mycotoxins had moderate to high concentrations (greater than $2 \mathrm{ppm}$ ). Deoxynivalenol was the most commonly 


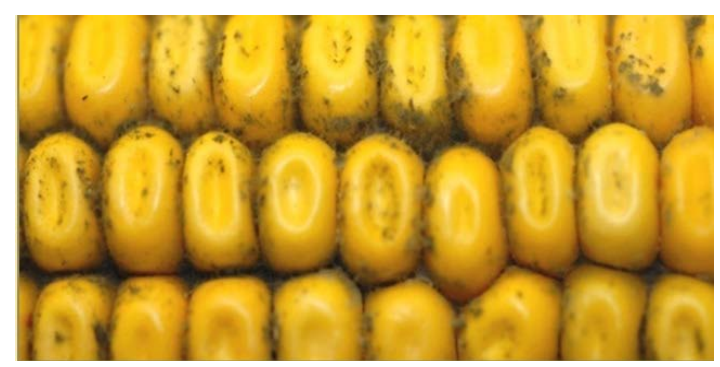

Figure 1. Cladosporium on corn kernel surfaces and in between corn kernels.

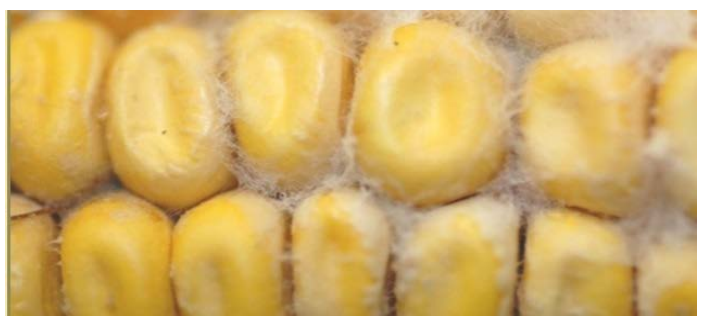

Figure 2. Fusarium pale pink mycelium on corn kernel surfaces and in between corn kernels.

Table 2. Frequency of detecting fungi species on corn ear samples collected in 2009 in North Dakota.

\begin{tabular}{cc}
\hline Fungi detected & Number of samples with detected fungi (out of 94) \\
\hline Cladosporium & 91 \\
Suspected Fusarium & 16 \\
Unidentified hyaline hyphomycete & 22 \\
Unidentified dematiaceous hyphomycete & 6 \\
Alternaria & 3 \\
Penicillium & 2 \\
Aureobsidium & 5 \\
Rhizopus & 5 \\
Stemphylium & 1 \\
\hline
\end{tabular}

Table 3. The levels and frequency of mycotoxins detected alone or in combination on corn ear samples collected in 2009 in North Dakota.

\begin{tabular}{|c|c|c|c|c|c|c|}
\hline \multirow[t]{2}{*}{ Mycotoxin detected } & \multicolumn{5}{|c|}{ Mycotoxin level detected (ppm) } & \multirow{2}{*}{ Total number } \\
\hline & $<0.5$ & $0.5-1.0$ & $1.0-2.0$ & $2.0-5.0$ & $>5.0$ & \\
\hline Only deoxynivolenol all forms & 2 & 6 & 1 & 0 & 0 & 9 \\
\hline Only T-2 and/or TH-2 & 4 & 1 & 2 & 1 & 0 & 8 \\
\hline Only zearalenone & 0 & 0 & 0 & 0 & 0 & 0 \\
\hline Only nivalenol & 0 & 1 & 1 & 0 & 0 & 2 \\
\hline Deoxynivolenol plus zearalenone & 1 & 0 & 0 & 1 & 1 & 3 \\
\hline Deoxynivolenol plus T2/TH2 & 1 & 1 & 0 & 0 & 0 & 2 \\
\hline Deoxynivolenol plus nivalenol & 0 & 0 & 1 & 0 & 0 & 1 \\
\hline Total number of positive samples & 8 & 9 & 5 & 2 & 1 & 25 \\
\hline
\end{tabular}


Table 4. Levels of detected mycotoxins in relation to swine and cattle feed level guidelines ${ }^{\mathrm{a}}$.

\begin{tabular}{ccccc}
\hline \multirow{2}{*}{ Mycotoxin } & \% of samples & Level $(\mathrm{ppm})$ & \multicolumn{2}{c}{ Maximum level for final ration (ppm) } \\
\cline { 4 - 5 } None detected & 73 & - & Pigs & Beef cattle \\
Deoxynivalenol & 17 & 73\% of positives $<1.0$ (range $0.2-12.9)$ & - & 10 \\
T-2 or HT-2 & 10.6 & $60 \%$ of positives $<0.5$ (range $0.2-2.7)$ & 5 & 5 \\
Zearalenone & 3.2 & $0.3-1.4$ & 0.5 & 10 \\
Nivalenol & 3.2 & $0.5-1.4$ & Not established & Not established \\
\hline
\end{tabular}

${ }^{\mathrm{a}}$ Guidelines for deoxynivalenol from the US Food and Drug administration [13]. Guidelines for T-2, HT-2 and zearalenone have not been established by the FDA and values indicated are based on suggestions from the NDSU Veterinary Diagnostic Lab.

detected toxin. However, of the samples that tested positive for deoxynivalenol, $73 \%$ had less than 1 ppm. The relatively low level of deoxynivalenol and the absence of zearalenone may be related to the relatively low temperatures encountered during grain filling and field dry down. Deoxynivalenol production has been reported to be favored by temperatures significantly higher than those reported during grain filling in this study [10]. Though zearalenone and nivalenol can be produced at lower temperatures than deoxynivalenol, the temperatures we report are lower than the lowest temperatures evaluated and are probably below the optimum range for the production of these mycotoxins [10] [11]. In a survey conducted in Serbia, detectable levels of deoxynivalenol were found in 43 and 50 percent of samples in 2004 and 2005, respectively [12].

All samples, except one (deoxynivalenol at $12.9 \mathrm{ppm}$ ), had mycotoxin levels below the guidance level for beef cattle rations (Table 4). Most of the samples that tested positive for mycotoxins had levels below the guidance level for swine rations. Given the season's prevailing weather conditions that prolonged fungal growth, the mycotoxin levels observed were surprisingly very low. Deoxynivalenol levels in a survey conducted in Serbia were also very low, and were within the range considered safe for animal feed [12].

\section{Conclusions and Recommendations}

The weather conditions during the 2009 growing season in North Dakota were conducive for the development of corn ear molds and hence posed a risk for high grain mycotoxin contamination. Based on the previous twenty years of weather records, this season in North Dakota was atypical as far as the environment was concerned. Therefore, it is not surprising that widespread fungal development on corn has not previously been a concern in North Dakota. Nevertheless, the probability of a repeat of this situation is possible. We found that although fungal growth was identified on most of the samples that were analyzed, very low mycotoxin contamination was detected. This suggests that even if conditions are favorable for molds to develop late in the season, mycotoxins will not necessarily be present and therefore reduce the feeding and food value of the grain. These data do suggest, however, that mycotoxins can still be a problem at a low frequency, even when environmental conditions are not optimal for Fusarium development. Though there is nothing that a farmer can do to mitigate the effects of the environment, a few things that can be considered to reduce the impact of molds that might develop are: use of hybrids that are resistant to common insect damage to ears, early harvest of fields with ear molds, minimizing kernel damage during harvesting, quickly drying harvested grain to less than $15 \%$ and storage at less than $7.2^{\circ} \mathrm{C}$ [3] [8].

\section{Acknowledgements}

The authors are grateful to the North Dakota Corn Council for their financial support of the research reported here.

\section{References}

[1] White, D.G. (1999) Compendium of Corn Diseases. 3rd Edition, American Phytopathological Press, St. Paul.

[2] Whitlow, L.W. and Hagler, W.M. (2004) The Top Ten Most Frequently-Asked Questions about Mycotoxins, Cattle and Dairy Food Products. In: Nutritional Biotechnology in the Feed and Food Industries. Proceedings of Alltech's $20^{\text {th }}$ 
Annual Symposium: Re-Imagining the Feed Industry, Lexington, Kentucky, 231-253.

[3] Robertson, A., Elmore, R. and Hurburgh, C. (2009) Corn Quality Issues_Field Molds. Integrated Crop Management News. Iowa State University. http://www.extension.iastate.edu/CropNews/2009/1015robertsonelmorehurburgh.htm

[4] Ransom, J.K. (2009) Cool Spring Weather-What Is It Good for? North Dakota Climate Bulletin, 3, $20-21$.

[5] NDAWN (2015) North Dakota Agricultural Weather Network. http://ndawn.ndsu.nodak.edu/

[6] Mirocha, C.J., Kolaczkowski, E., Xie, W., Yu, H. and Jelen, H. (1998) Analysis of Deoxynivalenol and Its Derivatives (Batch and Single Kernel) Using Gas Chromatography/Mass Spectrometry. Journal of Agriculture and Food Chemistry, 46, 1414-1418.

[7] Mullins, B. (2009) Weather Highlights. North Dakota Climate Bulletin, 3, 2-6.

[8] Patience, J. and Steve, D.V. (2010) Mycotoxin Contamination of Corn. Iowa State University Extension. http://www.ipic.iastate.edu/publications/IPIC12.pdf

[9] Sutton, J.C. (1982) Epidemiology of Wheat Blight and Maize Ear Rot Caused by Fusarium graminearum. Canadian Journal of Plant Pathology, 4, 195-209.

[10] Martins, M.L. and Martins, H.M. (2002) Influence of Water Activity, Temperature and Incubation Time on the Simultaneous Production of Deoxynivalenol and Zearalenone in Corn (Zea mays) by Fusarium graminearum. Food Chemistry, 79, 315-318.

[11] Llorens, A., Mateo, R., Hinojo, M.J., Valle-Algarra, F.M. and Jimenez, M. (2004) Influence of Environmental Factors on the Biosynthesis of Type B Trichothecenes by Isolates of Fusarium spp. from Spanish Crops. International Journal of Food Microbiology, 94, 43-54.

[12] Jajic, I., Juric, V. and Abramovic, B. (2008) First Survey of Deoxynivalenol Occurrence in Crops in Serbia. Food Control, 19, 545-550.

[13] FDA (2015) Guidance for Industry and FDA: Advisory Levels for Deoxynivalenol (DON) in Finished Wheat Products for Human Consumption and Grains and Grain By-Products Used for Animal Feed. http://www.fda.gov/downloads/Food/GuidanceRegulation/UCM217558.pdf 